\title{
Parallel Relational Universes - experiments in modularity
}

\author{
Luigi Pagliarini $^{1,2}$, Henrik Hautop Lund ${ }^{1}$ \\ Centre for Playware, Technical University of Denmark, 2800 Kgs. Lyngby, Denmark \\ ${ }^{2}$ Academy of Fine Arts of Macerata, Via Berardi, 6, 405111 Macerata, Italy \\ luigipagliarini@gmail.com \\ www.playware.dk
}

\begin{abstract}
We here describe Parallel Relational Universes, an artistic method used for the psychological analysis of group dynamics. The design of the artistic system, which mediates group dynamics, emerges from our studies of modular playware and remixing playware. Inspired from remixing modular playware, where users remix samples in the form of physical and functional modules, we created an artistic instantiation of such a concept with the Parallel Relational Universes, allowing arts alumni to remix artistic expressions. Here, we report the data emerged from a first pre-test, run with gymnasium's alumni. We then report both the artistic and the psychological findings. We discuss possible variations of such an instrument. Between an art piece and a psychological test, at a first cognitive analysis, it seems to be a promising research tool.
\end{abstract}

Keywords: Art, Playware, Modular Technology, Remixing Playware, Social Art.

\section{Introduction}

Parallel Relational Universes (URP) is an attempt, both artistic and scientific, to conceive a method to investigate the small groups psycho-dynamics expressed throughout a Relational Modularity logic into a graphical modality.

The project is located in between an artistic conception and a psychological need of a new method for small groups' analysis, since it aspires at catching the "essence" of a group by materializing and framing the social interaction into a unique graphical expression resulting from a collective action. All of that, to look for tangible artefacts that might be "witnesses" of small groups' dynamics readable throughout a Psychology of Shape analysis. In other words, the basic assumption is that the emerging shape might reveal the psychological structure of the related group.

URP was inspired by different artistic, psychological and informatics sources as the Cadavre exquis [1], the Pittura Stocastica [2], the Tree Testing Tool [3], Modular Tiles [4], Remixing Playware [5].

Such playware is defined as intelligent hardware and software that creates play and playful experiences for users of all ages $[6,7]$, and R\&D in playware has led to numerous applications in various areas such as rehabilitation [4, 8], playgrounds [7], education [9], art
[10], and sport [11]. In all such cases, users interact with the playware as a free and voluntary activity that they engage in for the pleasure of play, even if the activity may be shown to have collateral effects e.g. in terms of health and skills. It has been proposed that modular playware is of particular interest to develop solutions for such varied areas of application, since modularity may facilitate easy assembly and adaptation of the playware to different interaction modalities [12]. We can view the modular playware as enabling the user to remix with modules to combine and construct new playware solutions.

Indeed, the proposed design of the artistic system, which mediates group dynamics, emerges from our studies of modular playware [12] and remixing playware [5]. Inspired from remixing modular playware, where users remix samples in the form of physical and functional modules, we created an artistic instantiation of such a concept with the Parallel Relational Universes, allowing arts alumni to remix artistic expressions.

Remixing playware has been defined [6, 7] to allow sampling and remixing of both physical and functional aspects of a system. Such remixing playware has a number of distinguished features which include: userconfigurable modularity, which allows the users to interact and manipulate with samples; user-guided behavior-based system, which allows compositions to 
emerge from the way performers interact with the "instruments" that provide the primitive behaviours; intelligent sampling as the ability of creating samples that allow anybody to remix with the samples ensuring an engaging outcome.

When created in the right manner, playware can mediate social creativity, as exemplified with the MusicTiles MagicCubes, which allow anybody in an easy and intuitive way to remix music samples according to their individual taste $[5,13]$. Designing and developing the samples in large, soft forms as $1 \mathrm{~m} 3$ cubes pushes the users into social interaction, since a user will only be able to control one instrument (sample set) himself, and will have to coordinate actions with other people to create/perform a remix. As a social playware, such a system explores the cooperative creativity: the MagicCubes seamless push the users into social play dynamics resulting in the users interacting and cooperating in their play to create and perform their collective new hit song versions.

The first pilot study of Parallel Relational Universes [14] was run with an analogical method and conducted with the alumni of an Italian art school, and its output has been exhibited to the public as an art piece while, below, we describe an automated ALife version of the same concept that allows the widening of the method to larger and more heterogeneous audiences.

\section{Description and Procedure}

The first, analogical, version of URP was conceived to be an "art game" with as simple as possible procedure so that it might consent to any people of any age to be involved in the building of the art piece. Indeed, we only used a dichromatic scale (black and white) and we gave users very easy instructions/suggestions/rules. In particular 3 of them: A. a strict rule; B. an elastic demand; C. a suggestion (that we then defined as almosta-rule).

The procedure itself was the following one. Once individualized and chosen a specific group, it was summoned in a room and given to each component (i.e. in our first experiment art gymnasium alumni) an expressive module (i.e. in this case a canvas). Later we imparted the group of participants with a general disposition (B. elastic demand) to freely locate themselves in the physical space so to get close to each other. We moved from the in part prejudicial idea that the group elements would convey to spatial subgroups based on a continuum of interpersonal relational, emotional and affective forces.

After that, we asked participants to paint the canvases in two specific colours, black (or white) as background and white (or black) as foreground. We strongly, but not strictly, suggested (C. almost-a-rule) to cover $50 \%$ of the space with the foreground colour leaving the resting $50 \%$ for the background.

Finally, we introduced the unique must (A. rule) which is the continuity of the sign (or gesture/geometry) on each and every side of the module-borders where a module collide with other modules (see Figure 1). In other words, each canvas border has to shape a continuous drawing with the neighbourhood and each and every executor has to negotiate such drawing with all of its neighbours. There must be a perfect continuity in each direction, north, east, west, south, south-west, etc.

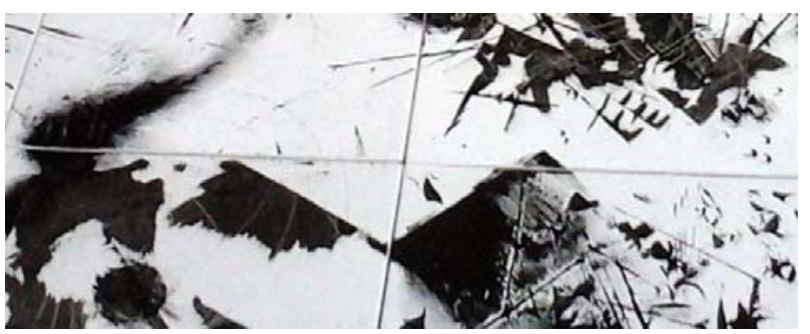

Figure 1.

Tiles' borders must are continuous.

The A rule has been introduced both for aesthetical purposes and, mainly, to push people interactivity which is necessary to highlight the pre-existing and emerging conflicts. (Those, indeed, are very descriptive of the specific group dynamic).

Besides those described above, two more rules/possibilities emerged from the interaction with the alumni: D. the Good Neighborhood; E. the Teleport. Shortly, the first one (i.e. D) is a negotiation, which allows one painter to penetrate (i.e. in a more or less reciprocal way) into others' painters canvases. The second one (i.e. E) is a negotiation, which allows the executor to engrave a far canvas with his/her sign. Both the emerging behaviours where kept because useful for both the aesthetic aspects and the psychological analysis of the behaviours.

\section{Hypothesis and Results}

Paintings realized with the URP method will tend to 
structure around an unpredictable shape. On the contrary, they will be largely descriptive (i.e. in terms of shape) of most of the group dynamics, while poorly suffering for the interfering chaotic and occasional intervening factors. The supervisor can, as well, decide if the painting is to be a unity or can be spontaneously subdivided in islands (i.e. emerging subgroups).

The theoretical hypothesis serving the entire model is that the group dynamics will force the execution towards a specific result, which can be interpreted both under the morphological and the graphical point of view. The two elements, besides all the aesthetical aspects, will be able to depict many of the group, such as cohesion, collaboration, competition, harmony, conflicts, etc. , as well as to describe most of the group members' personality as, for example, dominant or gregarious, weak or strong, aggressive or myths, timid or extrovert, etc.

The URP method discloses and reports, through the signs, the innumerable groups' dynamics. It camouflages with the pictorial context those behavioural rules and regulations that could result heavy, bulky or frustrating in other circumstances. Such an influence will bring to a semiotic drift the whole system, transforming the experience in a highly descriptive expression of a particular group in a particular historical moment of its existence.

The administration of our relational painting game has produced appreciable results in, at least, three domains of knowledge: Education-Pedagogy; Psychology-Sociology; Art. Although, for this very first trial we have made no measurements, all the teachers and professors involved in the experiment agreed on the extreme efficiency of the method under the motivational point of view. In particular, it has been underlined that, educationally, it pushes in a quite gentle way the young students at dealing with "abstract representations", a pretty difficult theme to communicate in normal classes. At the very same time, pedagogically speaking, it impresses and forces the classes into a cooperative and collaborative modality that is both practical (i.e. alumni have to do) and theoretical (i.e. alumni have to understand). This last consideration drives us directly to the most important aspect of the game, the extremely strong interactive modality the game carries along with itself. Indeed, under a psychological and sociological light, the URP method plays with the concept of individuality as counterweighted to the idea of sociality. The students ego - defined as peripersonal and interpersonal space - is solicited both in terms of virtual and physical boundaries. More than that, the playful and pitoric spirit of the game makes it so that even the weakest personalities can easily deal with the concept of borders and improve their capacity in mediating social actions without getting scared. Therefore, it has to be noticed that, URP for the very same reasons kind of stimulate the selfconsciousness of both aggressive and remissive personalities. This makes of it a good candidate has method to be used in art-therapy.

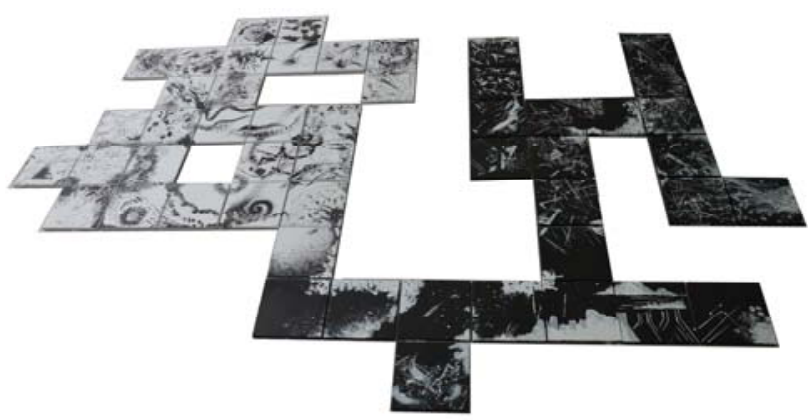

Figure 2.

Aesthetical results.

Under the artistic point of view, URP instantiates a new approach to modularity that allows users to play with the shape (i.e. intended as painting and painting content) in a deep and articulated way. In other words, it proposes an escape from canonical painting shape (see Figure 2), opening up to a number of geometrical solutions, which can be perceived as unlimited.

\section{Discussion}

As a matter of facts, the URP method idea is to build a projective test that can measure groups' dynamics (i.e. cooperation, collaboration, etc.) - psychodynamics of groups is reported in [15]. Such a method, indeed, could catch particular structures of groups' cohesion (i.e. opening, esteem, trust, etc.) and desegregation (i.e. closing, mistrust, depreciation, etc.) returning them both in the form of geometry and in the form of interrelational aesthetical contents. That is why, besides any possible aesthetical consideration, the authors' interest was focused on building an instrument able to measure and predict psychological aspects of groups, and under this point of view this first attempt can be considered a great success. The hope is that in future we will be able to reiterate such an experiment with different groups of different ages so to properly measure, analyse and define 
unkown clusters of behaviour that can be found in small groups.

Indeed, the encouraging results obtained with the analogical instantiation of the URP method has driven us to move on to an automation of it, which could facilitate and speed up the testing.
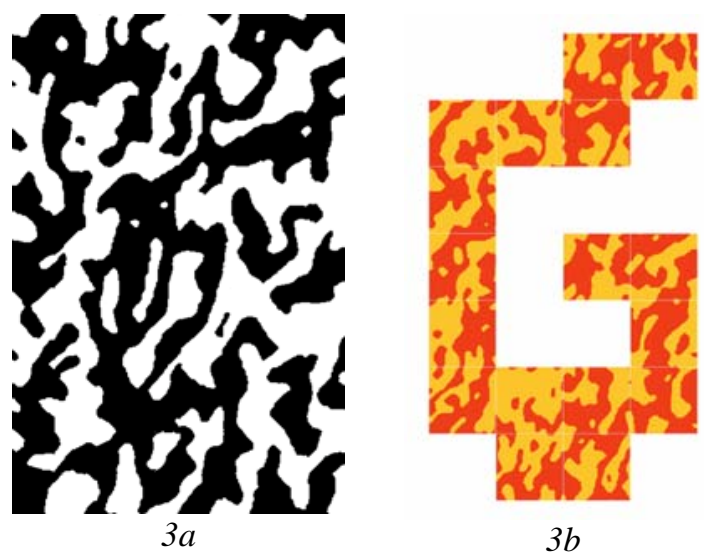

Figure $3 a$ and $3 b$

Two e-URP screenshots

At the moment a first instantion of such algorithm, called e-URP has taken its first steps, as shown in Figure 3a and $3 b$.

\section{Acknowledgement}

The author would like to thank Antonello Tolve, Parallelo $42^{\circ}$, the teachers Pierpaolo Serini, Amalia Ricci, Maria Valori, Silvia Volpe, and students of the Istituto Statale d'Arte "Bellisario-Misticoni" of Pescara, Italy.

\section{References}

[1] Alastair B.; Gooding M. Surrealist Games. London: Redstone Press. pp. 143-144. (1991).

[2] Lombardo S., Interpretazioni e preferenze di strutture casuali. Rivista di Psicologia dell'Arte anno XV, nn. 3-45, 1994, (1994)

[3] Crotti E., E tu che albero sei? Come interpretare la personalità attraverso il disegno dell'albero, Mondadori Ed. (2006).

[4] H. H. Lund. Modular Robotics for Playful Physiotherapy, in Proceedings of IEEE Int. Conference on Rehabilitation Robotics, IEEE Press, 571-575, 2009.

[5] Lund, H. H., Marti, P., \& Tittarelli, M. (2014, August). Remixing playware. In Robot and Human
Interactive Communication, 2014 RO-MAN: The 23rd IEEE International Symposium on (pp. 49-55). IEEE..

[6] H. H. Lund, and C. Jessen, "Playware - Intelligent technology for children's play." Technical Report TR2005-1, June, Maersk Institute, University of Southern Denmark, 2005.

[7] H. H. Lund, T. Klitbo, and C. Jessen, "Playware Technology for Physically Activating Play," Artificial Life and Robotics Journal, 9:4, 2005, pp. 165-174.

[8] H. H. Lund, "Modular Playware as a Playful Diagnosis Tool for Autistic Children." In Proceedings of IEEE International Conference on Rehabilitation Robotics, IEEE Press, 2009, pp. 899-904.

[9] H. H. Lund, P. Marti, "Physical and Conceptual Constructions in Advanced Learning Environments," Interaction Studies 5:2, 2004, pp. 269-299.

[10] H. H. Lund, M. Ottesen, "RoboMusic - A BehaviorBased Approach," Artificial Life and Robotics Journal, 12: 1-2, 2008, pp. 18-23.

[11] H. H. Lund, T. Thorsteinsson, "Social playware for mediating teleplay interaction over distance." International Journal Artificial Life and Robotics, 16:4, 2012, pp. 435-440.

[12] H. H. Lund, P. Marti, "Designing Modular Robotic Playware." In 18th IEEE International Symposium on Robot and Human Interactive Communication (Ro-Man 2009), IEEE Press, 2009, pp. 115-121.

[13] Pagliarini, L., \& Lund, H. H. (2012). MagicTiles. ALife for Real and Virtual RoboMusic. In Proc. of 17th International Symposium on Artificial Life and Robotics, ISAROB, Japan.

[14] Pagliarini L. Universi Relazionali Paralleli, Rivista di Psicologia dell'Arte, N.25 in stampa (2014).

[15] Di Maria F., Lo Verso G.. La psicodinamica dei gruppi. Teorie e tecniche. Cortina Raffaello Ed. (1995) 